\title{
HLA Class I or Class II and Disease Association: Catch the Difference If You Can
}

\author{
Maria Teresa Fiorillo, Fabiana Paladini, Valentina Tedeschi and Rosa Sorrentino* \\ Department of Biology and Biotechnology "Charles Darwin", Sapienza University of Rome, Rome, Italy
}

Keywords: HLA class I, HLA class II, autoimmune disease, T cell receptor, self-reactivity

The association of autoimmune diseases with HLA has been known for many decades. To date, however, the underlying mechanisms have not been fully understood.

The recently introduced genome-wide association studies (GWAS) have suggested that several genes converging in common pathways contribute to the genetic susceptibility in such disorders. Nevertheless, for most autoimmune/autoinflammatory diseases, the HLA genes are by far the strongest risk factors. The basis of some associations has now been elucidated, particularly in those cases in which exogenous factors are involved.

\section{DISEASES INVOLVING ANTI-SELF-REACTIVITY TRIGGERED BY KNOWN EXOGENOUS FACTORS}

Celiac disease (CD) is a complex disorder of the small intestine with a strong genetic component, which is caused by an inappropriate immune response to ingested wheat gluten. Gluten peptides are modified by the enzyme transglutaminase and loaded into the groove of specific DQ2 molecules. This event triggers a TCR-mediated cytokine cascade causing the pathology. In $95 \%$ of cases, the "guilty" molecule is the DQ2, whereas in the remaining $5 \%$, the gluten-derived peptides are presented by the DQ8 molecules (1-3).

The hypersensitivity to beryllium induces the chronic beryllium disease (CBD), another disorder in which the association with a specific polymorphic amino acid, Glu69, in the HLA-DP beta chain is well established. The presence of Glu69, together with a negatively charged amino acid at P4 of the peptide and two other negatively charged amino acids in the groove, allows the binding of beryllium to the HLA-DP molecules. This triggers a beryllium-specific polyclonal $\mathrm{T}$ cell response leading to inflammation and tissue damage (4-6).

Drug hypersensitivity could manifest in genetically predisposed subjects. An example is given by the anti-retroviral drug abacavir; this molecule can induce a hypersensitivity reaction in individuals positive for the HLA-B`5701 class I molecule. The mechanism has been disclosed, showing that abacavir settles into the F pocket of the HLA-B ${ }^{\star} 5701$ groove thus hampering the binding of the bulky tryptophan, the preferred C-terminal anchor for HLA-B ${ }^{\star} 5701$, which is thus substituted by either Ile or Leu. This changes the peptide repertoire by $25 \%$, unleashing a strong, HLA-restricted and anti-self-polyclonal CD8+ T cell response. The mechanism is highly specific and occurs in HLA-B ${ }^{\star} 5701$ but not in carriers of HLA- $B^{\star} 5702$ or HLA- $B \star 5703$ alleles differing from $B \star 5701$ for three or two amino acids at positions 114,116, and 156, respectively. These three positions have been shown to be relevant for the specificity of the F pocket as well as for the engagement of tapasin, a chaperon that binds the HLA-class I molecules in the ER $(7,8)$.

\section{DISEASES INVOLVING AN ANTI-SELF-REACTIVITY TRIGGERED BY UNDEFINED ENDOGENOUS FACTORS}

In other HLA-class II-associated autoimmune diseases, such as rheumatoid arthritis (RA) or type 1 diabetes (T1D), the triggering antigens are unknown, but there is no reason to believe that the mechanisms are different. Indeed, almost the entire association of HLA with RA can be ascribed to 
four HLA-DR amino acid positions (amino acids 11, 13, 71, and 74 in the beta chain) in the groove of the HLA-DR molecules which points to antigen presentation as disease trigger (9).

In the case of T1D, the presence of Asp57 in the HLA-DQ beta chain is strongly protective suggesting that it hampers the binding of diabetogenic self-peptide(s) $(10,11)$. A more refined 4-digit analysis has established that position 57 in the HLA-DQ $\beta 1$ by itself can explain $15.2 \%$ of the total phenotypic variance in T1D, increasing to $26.9 \%$ with the contribution of HLA-DR $\beta 1$ positions 13 and 71. The three positions together explained $90 \%$ of the phenotypic variance in the HLA-DRB1HLA-DQA1-HLA-DQB1 locus. These observations implicate, in addition to the pocket $\mathrm{P} 9$, the pocket $\mathrm{P} 4$ of the antigenbinding groove in the presentation of diabetogenic peptides (11). GWAS analysis has shown that other genes are involved in the triggering of the disease, but they are by far less relevant than HLA. Although some antigens such as preproinsulin have been found to be targets of the T cells, this involves only a proportion of patients (12).

\section{THE T CELL VIEWPOINT}

One open question is the nature of the TCRs causing the pathogenic $\mathrm{T}$ cell responses. In the case of $\mathrm{CD}$, the $\mathrm{T}$ cell response mimics an anti-self-recognition and, in the case of CBD, the subversion of the HLA-DP peptidome evokes a robust $\mathrm{T}$ cell response. However, in the other cases, the role of the $\mathrm{T}$ cells and the nature of the TCRs are far from being defined. It is a common belief that the effector $\mathrm{T}$ cell clones have to escape the thymic-negative selection. Therefore, they are likely to express low-affinity TCRs which need to be "woken up" by cross-reactive, presumably common pathogens, and/or by an inflammatory cascade (13). Although the existence of T regulatory cells is now well established, it is still hard to believe that the control of the autoreactivity depends entirely on such cells $(14,15)$. An alternative explanation is that novel "self" antigens are formed by mechanisms such as those discussed above or by post-transcriptional modifications.

\section{HLA-CLASS I-MEDIATED DISEASES}

It is interesting to note that the association of some diseases with HLA-class I has been regarded as an exception to the rule and, for each disease, specific mechanisms have been postulated. However, several observations point to a more unifying view.

Interestingly, position 116 in the F pocket of HLA-class I, which has been involved in the hypersensitivity to abacavir, plays also a pivotal role in the association of HLA-B ${ }^{\star} 27$ with ankylosing spondylitis (AS). In this case, the HLA-B ${ }^{\star} 27$ subtypes associated with AS possess an Asp at position 116, replaced in the non-disease predisposing alleles by a different amino acid (Tyr in $B^{\star} 2706$ and His in $B^{\star} 2709$ ). HLA- $B^{\star} 2707$, whose association with AS appears less robust, has also a Tyr at position 116 that, however, comes together with another constellation of polymorphic residues (16-18). Actually, the F pocket of these HLA molecules is relevant for peptide accommodation and influences the flexibility of the entire molecule and the surface area seen by the TCR (19).

It is tempting to speculate that, as in the case of abacavir or beryllium, small molecules could intrude into the pocket and dramatically change the peptide repertoire from "self" to "nonself." This would make pointless the effort to single out specific pathogenic peptide(s).

The crucial role of the antigen presentation in the onset of disease is also indicated by the observation that at least three HLA-class I-associated diseases, AS, Behçet, and psoriasis (Ps), associated with HLA-B ${ }^{\star} 27, \mathrm{HLA} \mathrm{B}^{\star} 51$, and HLA-C ${ }^{\star} 06$, respectively, share an association with ERAP1. This is an aminopeptidase of the ER which shapes the peptide repertoire of the HLA class I molecules. Interestingly, the association only occurs in patients possessing the susceptible HLA class I allele, demonstrating an epistatic interaction between the two genes $(20,21)$.

Even more intriguing is the observation that HLA-B ${ }^{\star} 27$, HLA$B^{\star} 51$, and HLA-C $C^{\star} 06$ together with HLA-B ${ }^{\star} 5701$ are the strongest protective alleles toward HIV infection $(22,23)$. It has been observed that some of the immunodominant peptides presented by these alleles are less prone to mutations because of structural and functional constraints. As an example, HLA-B27-positive individuals show a reactivity against the immunodominant epitope (KK10 epitope) of the HIV p24/Gag. Viral escape in this case implies the loss of the P2 anchor. However, this mutation is not structurally acceptable for the virus unless a second mutation within the same epitope does occur, an extremely unlikely event (24). It is also possible that a broader polyfunctionality and a higher functional avidity of the virus-specific cytotoxic CD8 T cells restricted for these alleles, allow to mount a wide and effective response, that is eventually redirected against "self" antigens. Indeed, at least in the case of HLA-B ${ }^{\star} 27$, the protection extends to hepatitis $\mathrm{C}$ virus as well (25).

Another disease strongly associated with HLA-class I is the Birdshot Chorioretinopathy, a rare form of posterior uveitis, in which $85-97.5 \%$ of patients are HLA-A ${ }^{\star} 29$ positive. The disease shows an association with ERAP2, another ER aminopeptidase involved in peptide trimming (26). ERAP2 also associates with AS in both HLA-B ${ }^{\star} 27$-positive and -negative patients (27) and to Ps (28), reinforcing the idea that the shaping of the peptide repertoire is crucial for these diseases to occur, even in the absence of the "legitimate" HLA molecule.

\section{AN EVOLUTIONARY GLANCE}

It is also possible, although difficult to demonstrate, that these "special" HLA-class I alleles have been selected in the course of evolution by devastating epidemics. In this context, it is interesting to note the uneven distribution of some of these alleles and the associated diseases. For instance, HLA-B ${ }^{\star} 51$ frequency varies along a path reminiscent of the silk road $(29,30)$, or the positive correlation between the distance from the equator and the prevalence of Ps (31) as well as the distribution of HLA-B ${ }^{\star} 27$ along a north to south gradient $(32,33)$. Interestingly, this correlates also with the strength of association raising a neglected but relevant question: how much the HLA-associated diseases do share with the same disorders lacking the relevant HLA alleles? 
TABLE 1 | HLA-class I and -class II-associated diseases and key polymorphic positions.

\begin{tabular}{|c|c|c|c|c|c|}
\hline Disease & HLA-associated allele & Position & Amino acid & Pocket & Reference \\
\hline Ankylosing spondylitis & HLA-B*27 & 116 & Asp & $\mathrm{F}$ & $(16)$ \\
\hline Psoriasis & HLA-C*06 & 156 & Trp & $\mathrm{F}$ & $(28)$ \\
\hline Chronic beryllium disease & HLA-DPB1 & 69 & Glu & P4 & (4) \\
\hline Rheumatoid arthritis & HLA-DRB1 & $11,13,71,74$ & Val, His, Lys, Ala & P4 & (9) \\
\hline Celiac disease & HLA-DQB1 & 71 & Lys & P4 & (34) \\
\hline Type 1 diabetes & HLA-DQB1 & 57 & Non-Asp & P9 & (35) \\
\hline Multiple sclerosis & HLA-DRB1*1501 & $71,74,57$ & Ala, Ala, Asp & P9 & (36) \\
\hline
\end{tabular}

Family studies on the inheritance of these non-canonical forms of the disease could be helpful but the genetics of these cohorts is hampered by the low number of subjects and by the heterogeneity of the diseases.

\section{NEW IDEAS FROM RECENT FINDINGS}

Hence, we propose here that the association between HLA-class I and HLA-class II with diseases is based on similar mechanisms and can be regarded as a unicum. In some diseases such as gluten intolerance, a specific antigen has the strength to activate a robust $\mathrm{T}$ cell response, in some others such as CBD or abacavir hypersensitivity, small molecules can dramatically interfere with the peptide repertoire thus sensitizing "dormant" $\mathrm{T}$ cell clones and unleashing an inflammatory cascade (Table 1).

The latter model is applicable also to other diseases such as AS where a couple of residues in the $\mathrm{F}$ pocket make the difference and for which many efforts have not produced a definitive explanation so far. This model could possibly account also for the tissue specificity observed in some diseases, if one speculates that the triggering molecules, which could be as small as a metal ion, are more abundant in some tissues as observed in the case of CBD. Of note, there are some HLA alleles which confer susceptibility to different diseases such as in the case of DQB $1^{\star} 0201$ which has been found associated with up to eight distinct diseases with different target tissues (37). In this context, there might be cases where unpredictable, newly generated epitopes can be expressed in a tissue-specific manner. It has been shown that the proteasome, which is the factory for HLA-class I epitopes, can generate peptides that are spliced together from two different fragments of the same protein and that this pool accounts for one-fourth of the entire immunopeptidome. This event can happen in a tissue-specific manner and generate novel epitopes. This unique set of antigens are therefore excellent candidates as triggers for autoimmunity (38).

RNA modifications such as RNA editing can yield new epitopes by inducing post-transcriptional modifications of the RNA sequence (39). It has also been shown that even short RNAs, i.e., circular RNAs, which were thought to have a regulatory role, can indeed be translated and become the source of new epitopes (40). In addition, defective ribosomal products (DRiPs) are continuously produced under stress conditions and they have been shown to be processed and presented (41).

All these mechanisms can, in particular conditions and in a tissue-specific manner, generate altered self that can unleash a
$\mathrm{T}$ cell response. In this context, a recent study showed that in T1D, the DRiPs translated from a reading-frame shifted sequence in insulin mRNA, can generate new epitopes, which can bind the susceptible HLA-DQ8 molecules (42). These epitopes are ignored by the immune system because produced under particular conditions and can therefore induce a specific T cell response. Most intriguingly, this same epitope has been shown to contextually bind the HLA-A2 class I molecules and therefore trigger a cytotoxic $\mathrm{T}$ cell response against the insulin-producing pancreatic beta cells in the HLA-A2-positive individuals (42). In support of these observations, GWAS have shown independent associations of several autoimmune diseases with both HLA-class I and HLAclass II regions.

Remarkably, new findings have now been published demonstrating that CD4 and CD8 T cells from patients with Parkinson's disease recognize $\alpha$-synuclein peptides displayed by both HLA-class II and class I molecules, respectively. Similar to other autoimmune diseases, only a fraction of Parkinson's patients responds to the same peptides leaving room for still unknown antigens. Of note, the presenting HLA-class II alleles had been previously described as weakly associated with the disease (43). This indicates that autoimmune mechanisms can extend to many different diseases, even in the absence of a robust HLA association.

In conclusion, to disentangle the immunopathogenesis of autoimmune diseases, we probably need to look at metabolic pathways that can broaden the spectrum of epitopes rather than evoking overturnings in the homeostasis of the immune responses. Newly generated epitopes eventually produced by stressed cells or the subversion of the peptidome by small molecules can unleash an everlasting anti-self $\mathrm{T}$ cell response.

\section{AUTHOR CONTRIBUTIONS}

MF discussed the opinion approach, selected the bibliography, and drafted the manuscript. FP and VT critically reviewed and edited the manuscript. RS searched the literature and wrote the manuscript. All the authors read and approved the final manuscript.

\section{ACKNOWLEDGMENTS}

The authors wish to thank Ceschina Foundation and Sapienza (Progetti di Ateneo) for financial support. 


\section{REFERENCES}

1. Sollid LM, Jabri B. Triggers and drivers of autoimmunity: lessons from coeliac disease. Nat Rev Immunol (2013) 13(4):294-302. doi:10.1038/nri3407

2. Molberg O, Mcadam SN, Körner R, Quarsten H, Kristiansen C, Madsen L, et al. Tissue transglutaminase selectively modifies gliadin peptides that are recognized by gut-derived T cells in celiac disease. Nat Med (1998) 4(6):713-7. doi:10.1038/nm0698-713

3. Shan L, Molberg $\varnothing$, Parrot I, Hausch F, Filiz F, Gray GM, et al. Structural basis for gluten intolerance in celiac sprue. Science (2002) 297(5590):2275-9. doi:10.1126/science.1074129

4. Richeldi L, Sorrentino R, Saltini C. HLA-DPB1 glutamate 69: a genetic marker of beryllium disease. Science (1993) 262(5131):242-4. doi:10.1126/ science. 8105536

5. Fontenot AP, Falta MT, Kappler JW, Dai S, McKee AS. Beryllium-induced hypersensitivity: genetic susceptibility and neoantigen generation. J Immunol (2016) 196(1):22-7. doi:10.4049/jimmunol.1502011

6. Lombardi G, Germain C, Uren J, Fiorillo MT, du Bois RM, JonesWilliams W, et al. HLA-DP allele-specific $\mathrm{T}$ cell responses to beryllium account for DP-associated susceptibility to chronic beryllium disease. J Immunol (2001) 166(5):3549-55. doi:10.4049/jimmunol.166.5.3549

7. Illing PT, Vivian JP, Dudek NL, Kostenko L, Chen Z, Bharadwaj M, et al. Immune self-reactivity triggered by drug-modified HLA-peptide repertoire. Nature (2012) 486(7404):554-8. doi:10.1038/nature11147

8. Norcross MA, Luo S, Lu L, Boyne MT, Gomarteli M, Rennels AD, et al. Abacavir induces loading of novel self-peptides into HLA-B*57:01: an autoimmune model for HLA-associated drug hypersensitivity. AIDS (2012) 26(11):F21-9. doi:10.1097/QAD.0b013e328355fe8f

9. Raychaudhuri S, Sandor C, Stahl EA, Freudenberg J, Lee HS, Jia X, et al. Five amino acids in three HLA proteins explain most of the association between MHC and seropositive rheumatoid arthritis. Nat Genet (2012) 44(3):291-6. doi:10.1038/ng.1076

10. Wållberg M, Cooke A. Immune mechanisms in type 1 diabetes. Trends Immunol (2013) 34(12):583-91. doi:10.1016/j.it.2013.08.005

11. Hu X, Deutsch AJ, Lenz TL, Onengut-Gumuscu S, Han B, Chen WM, et al. Additive and interaction effects at three amino acid positions in HLA-DQ and HLA-DR molecules drive type 1 diabetes risk. Nat Genet (2015) 47(8):898-905. doi:10.1038/ng.3353

12. Skowera A, Ellis RJ, Varela-Calvino R, Arif S, Huang GC, Van-Krinks C, et al. CTLs are targeted to kill $\beta$ cells in patients with type 1 diabetes through recognition of a glucose-regulated preproinsulin epitope. J Clin Invest (2008) 118(10):3390-402. doi:10.1172/JCI35449

13. Bouziat R, Hinterleitner R, Brown JJ, Stencel-Baerenwald JE, Ikizler M, Mayassi T, et al. Reovirus infection triggers inflammatory responses to dietary antigens and development of celiac disease. Science (2017) 356(6333):44-50. doi:10.1126/science.aah5298

14. Shevach EM. Mechanisms of foxp3 + T regulatory cell-mediated suppression. Immunity (2009) 30(5):636-45. doi:10.1016/j.immuni.2009.04.010

15. Overacre AE, Vignali DA. T(reg) stability: to be or not to be. Curr Opin Immunol (2016) 39:39-43. doi:10.1016/j.coi.2015.12.009

16. D’Amato M, Fiorillo MT, Carcassi C, Mathieu A, Zuccarelli A, Bitti PP, et al. Relevance of residue 116 of HLA-B27 in determining susceptibility to ankylosing spondylitis. Eur J Immunol (1995) 25(11):3199-201. doi:10.1002/ eji.1830251133

17. Sorrentino R, Böckmann RA, Fiorillo MT. HLA-B27 and antigen presentation: at the crossroads between immune defense and autoimmunity. Mol Immunol (2014) 57(1):22-7. doi:10.1016/j.molimm.2013.06.017

18. Gómez P, Montserrat V, Marcilla M, Paradela A, de Castro JA. B ${ }^{\star} 2707$ differs in peptide specificity from $B^{\star} 2705$ and $B^{\star} 2704$ as much as from HLA-B27 subtypes not associated to spondyloarthritis. Eur J Immunol (2006) 36(7):1867-81. doi:10.1002/eji.200635896

19. Fabian H, Huser H, Loll B, Ziegler A, Naumann D, Uchanska-Ziegler B. HLAB27 heavy chains distinguished by a micropolymorphism exhibit differential flexibility. Arthritis Rheum (2010) 62(4):978-87. doi:10.1002/art.27316

20. Evans DM, Spencer CC, Pointon JJ, Su Z, Harvey D, Kochan G, et al. Interaction between ERAP1 and HLA-B27 in ankylosing spondylitis implicates peptide handling in the mechanism for HLA-B27 in disease susceptibility. Nat Genet (2011) 43(8):761-7. doi:10.1038/ng.873
21. McGonagle D, Zehra Aydin S, Gül A, Mahr A, Direskeneli A. MHC-I-opathy'unified concept for spondyloarthritis and Behçet disease. Nat Rev Rheumatol (2015) 11(12):731-40. doi:10.1038/nrrheum.2015.147

22. Pereyra F, Jia X, McLaren PJ, Telenti A, de Bakker PI, Walker BD, et al. The major genetic determinants of HIV-1 control affect HLA class I peptide presentation. Science (2010) 330(6010):1551-7. doi:10.1126/science.1195271

23. Zhang Y, Peng Y, Yan H, Xu K, Saito M, Wu H, et al. Multilayered defense in HLA-B51-associated HIV viral control. J Immunol (2011) 187(2):684-91. doi:10.4049/jimmunol.1100316

24. Schneidewind A, Brockman MA, Sidney J, Wang YE, Chen J, Suscovich TJ, et al. Structural and functional constraints limit options for cytotoxic T-lymphocyte escape in the immunodominant HLA-B27-restricted epitope in human immunodeficiency virus type 1 capsid. J Virol (2008) 82:5594-605. doi:10.1128/JVI.02356-07

25. Rao X, Hoof I, van Baarle D, Keşmir C, Textor J. HLA preferences for conserved epitopes: a potential mechanism for hepatitis $\mathrm{C}$ clearance. Front Immunol (2015) 6:552. doi:10.3389/fimmu.2015.00552

26. Kuiper JJ, Van Setten J, Ripke S, Van 'T Slot R, Mulder F, Missotten T, et al. A genome-wide association study identifies a functional ERAP2 haplotype associated with birdshot chorioretinopathy. Hum Mol Genet (2014) 23(22):6081-7. doi:10.1093/hmg/ddu307

27. Robinson PC, Costello ME, Leo P, Bradbury LA, Hollis K, Cortes A, et al. ERAP2 is associated with ankylosing spondylitis in HLA-B27-positive and HLA-B27-negative patients. Ann Rheum Dis (2015) 74(8):1627-9. doi:10.1136/annrheumdis-2015-207416

28. Yin X, Low HQ, Wang L, Li Y, Ellinghaus E, Han J, et al. Genome-wide meta-analysis identifies multiple novel associations and ethnic heterogeneity of psoriasis susceptibility. Nat Commun (2015) 6:6916. doi:10.1038/ ncomms7916

29. Verity DH, Marr JE, Ohno S, Wallace GR, Stanford MR. Behçet's disease, the silk road and HLA-B51: historical and geographical perspectives. Tissue Antigens (1999) 54(3):213-20. doi:10.1034/j.1399-0039.1999.540301.x

30. Horie Y, Meguro A, Ohta T, Lee EB, Namba K, Mizuuchi K, et al. HLA-B51 carriers are susceptible to ocular symptoms of Behçet disease and the association between the two becomes stronger towards the east along the silk road: a literature survey. Ocul Immunol Inflamm (2017) 25(1):37-40. doi:10.3109/ 09273948.2015.1136422

31. Parisi R, Symmons DBM, Griffiths CEM, Ashcroft DM. Global epidemiology of psoriasis: a systematic review of incidence and prevalence. J Invest Dermatol (2013) 133(2):377-85. doi:10.1038/jid.2012.339

32. Mathieu A, Cauli A, Fiorillo MT, Sorrentino R. HLA-B27 and ankylosing spondylitis geographic distribution as the result of a genetic selection induced by malaria endemic? A review supporting the hypothesis. Autoimmun Rev (2008) 7(5):398-403. doi:10.1016/j.autrev.2008.03.013

33. Mathieu A, Paladini F, Vacca A, Cauli A, Fiorillo MT, Sorrentino R. The interplay between the geographic distribution of HLA-B27 alleles and their role in infectious and autoimmune diseases: a unifying hypothesis. Autoimmun Rev (2009) 8(5):420-5. doi:10.1016/j.autrev.2009.01.003

34. Bevan S, Popat S, Braegger CP, Busch A, O’Donoghue D, Falth-Magnusson K, et al. Contribution of the $\mathrm{MHC}$ region to the familial risk of coeliac disease. J Med Genet (1999) 36(9):687-90.

35. Todd JA, Bell JI, McDevitt HO. HLA-DQ beta gene contributes to susceptibility and resistance to insulin-dependent diabetes mellitus. Nature (1987) 329(6140):599-604. doi:10.1038/329599a0

36. Patsopoulos NA, Barcellos LF, Hintzen RQ, Schaefer C, van Duijn CM, Noble JA, et al. Fine-mapping the genetic association of the major histocompatibility complex in multiple sclerosis: HLA and non-HLA effects. PLoS Genet (2013) 9(11):e1003926. doi:10.1371/journal.pgen.1003926

37. Karnes JH, Bastarache L, Shaffer CM, Gaudieri S, Xu Y, Glazer AM, et al. Phenome-wide scanning identifies multiple diseases and disease severity phenotypes associated with HLA variants. Sci Transl Med (2017) 9(389): eaai8708. doi:10.1126/scitranslmed.aai8708

38. Liepe J, Marino F, Sidney J, Jeko A, Bunting DE, Sette A, et al. A large fraction of HLA class I ligands are proteasome-generated spliced peptides. Science (2016) 354(6310):354-8. doi:10.1126/science.aaf4384

39. Rossetti C, Picardi E, Ye M, Camilli G, D’Erchia AM, Cucina L, et al. RNA editing signature during myeloid leukemia cell differentiation. Leukemia (2017). doi:10.1038/leu.2017.134 
40. Tatomer DC, Wilusz JE. An unchartered journey for ribosomes: circumnavigating circular RNAs to produce proteins. Mol Cell (2017) 66(1):1-2. doi:10.1016/j.molcel.2017.03.011

41. Rock KL, Reits E, Neefjes J. Present yourself! By MHC class I and MHC class II molecules. Trends Immunol (2016) 37(11):724-37. doi:10.1016/j.it.2016.08.010

42. Kracht MJ, van Lummel M, Nikolic T, Joosten AM, Laban S, van der Slik AR, et al. Autoimmunity against a defective ribosomal insulin gene product in type 1 diabetes. Nat Med (2017) 23(4):501-7. doi:10.1038/nm.4289

43. Sulzer D, Alcalay RN, Garretti F, Cote L, Kanter E, Agin-Liebes J, et al. T cells from patients with Parkinson's disease recognize $\alpha$-synuclein peptides. Nature (2017) 546:656-61. doi:10.1038/nature22815
Conflict of Interest Statement: The authors declare that the research was conducted in the absence of any commercial or financial relationships that could be construed as a potential conflict of interest.

Copyright (c) 2017 Fiorillo, Paladini, Tedeschi and Sorrentino. This is an openaccess article distributed under the terms of the Creative Commons Attribution License (CC BY). The use, distribution or reproduction in other forums is permitted, provided the original author(s) or licensor are credited and that the original publication in this journal is cited, in accordance with accepted academic practice. No use, distribution or reproduction is permitted which does not comply with these terms. 